\title{
Research and Practice on Project-based Teaching for Ship Structure Design Course
}

\author{
Youwei Du \\ Qingdao Huanghai University, China
}

Keywords: ship structure design; project=based teaching; normative design

\begin{abstract}
Aiming at the contradiction between the curriculum and engineering of "ship structure design" and the students' lack of understanding, this paper takes a bulk carrier as the research object, carries out the whole process of project-oriented teaching, and expounds the design ideas and understanding of project-oriented teaching, providing reference for similar courses and practical teaching in colleges and universities.
\end{abstract}

\section{Introduction}

The Course of Ship Structure Design occupies a very important position in the cultivation of core competence of ship engineering technology. The course involves a wide range of knowledge and a high degree of practical engineering integration. If the software function module is used as the core to teach in the process of explanation, then the students will only understand the operation command and lack the ability to think actively. When they actually encounter the actual engineering problems, the knowledge they learn can't be learned ${ }^{[1]}$. Therefore, the introduction of project teaching is very necessary. The project teaching is based on the actual project, and the studentcentered teaching method is guided by the teacher.

Through investigations and visits to ship-going universities in Shandong Province, it was found that most of the ship-based colleges have successively introduced SPD systems and opened corresponding courses, basically in accordance with the contents of the Hudong training manual, according to the parameters initialization, plane plate rack Functional modules such as curved panel and bracket modeling, hull drawing report processing and output are taught and limited to guide students in simple modeling and basic operations. This kind of teaching mode makes students have no enthusiasm and initiative to learn. In order to change this situation, it is necessary to analyze and explain according to the structural area of the hull through project-driven forms, and calculate and plot the structural areas in groups to improve students. The enthusiasm of learning and teaching effects ${ }^{[2]}$.

Combined with the working mode of the ship design company, the course is completely divided from the perspective of production design practice, considering the actual situation of the students, the process of ship design is divided into specific engineering projects, and the tasks are assigned according to the requirements of each project.

Take a few typical sections of a certain part of a real ship as an example. Each section is an engineering project, and the process of explanation is completely in accordance with the project implementation process. In the specific teaching, first learn some example models to improve students' interest in learning. In the process, explain the content and regulations that should be considered in the segmentation design, from specification selection, material determination, profile selection to size calculation, completely in accordance with the actual design. The production process takes place. The concept of "project-focused" in this kind of teaching can play a role in explaining the software itself and strengthening the ability of students to use software to deal with practical problems.

\section{Implementation of Project-based Teaching Process}

The project adopts 65000DWT bulk carrier as the research object, combined with the "Steel 
Seagoing Classification Rules" ${ }^{\text {[3] }}$, the ship is first standardized calculation, and the minimum thickness of each outer plate and the minimum section mode of the profile are determined by the standard calculation results. To determine the size and form of each outer panel and structure, the project process is divided into five major segments, a total of 64 hours, that is, the hull structural design basis (8 lessons); data collection and preparation (2 lessons); total segment structure ( 2 lessons); structural specification calculation (24 lessons); segmented structure design (28 lessons).

First, explain the requirements of structural design, such as safety, manufacturability and economy. Under the requirements of the overall design of the ship, solve the design problems of the form of the hull structure, the dimensions and connections of the components, and ensure that the hull has the proper strength and Good technical and economic performance.

Secondly, the structural design method is explained, mainly adopting the normative design method, that is, according to the main scale and structural form of the ship, and various operational and construction requirements, the arrangement and scale of the components are determined according to the relevant provisions of the ship construction specifications formulated by the classification society. Then check the strength and structural stability.

Finally, the general provisions of the hull structure design are introduced to determine the general principles and regulations for the navigation area, use, materials, skeleton type and structural arrangement of the ship.

Collect the main dimensions and ship type parameters of the ship. Including the captain, width, depth, draught, etc., in addition to drawing the ship's profile, exporting the ship's type value file, including the rib profile, longitudinal profile and waterline, the data is for the hull The basis of structural specification calculations and structural design. The main scale and main scale factor of the 65000DWT bulk carrier used in the project are shown in Table 1.

Tab.1 Bulk carrier main scale and main scale coefficient

\begin{tabular}{ll}
\hline Parameter & value \\
\hline overall length $L_{\text {oa }}$ & $225 \mathrm{~m}$ \\
waterline length $L_{\text {wl }}$ & $201 \mathrm{~m}$ \\
length $L$ & $190 \mathrm{~m}$ \\
breadth $B$ & $32.2 \mathrm{~m}$ \\
depth $D$ & $18 \mathrm{~m}$ \\
draft $d$ & $12.5 \mathrm{~m}$ \\
Square factor $C_{b}$ & 0.79 \\
\hline
\end{tabular}

According to the "Code for Design of Sectional Sections of Hulls", the total section of the cargo hold is divided to determine the number and location of the sections. At this time, structural characteristics and strength, process and construction conditions, production planning and labor, and lifting and transportation should be fully considered. Capacity and length and location requirements for each segment. The teacher can emphasize the principle and general requirements of the division and the basis of the division of the total segment structure, and what effect this division has on the construction process and structure. Of course, after the segmentation of the segmentation is completed, each segment needs to be encoded. The segmentation code of each enterprise and each project is not the same. Here, the students can be explained according to the general coding principle, which includes: a Engineering code; b. segmentation code; c. operation phase code; d. group code; e. part type code; f. part code; g. jigsaw/processing code, etc. Structural Part Code Rules, which are not detailed here. For the sake of simplicity, the 65000 DWT bulk carrier cargo section can be divided into 4 sections, namely the bottom section, the side section, the deck section and the bulkhead section.

According to the CCS Rules for Classification of Sea-Going Steel Ships (2015), the calculation results of the main structural dimensions of the cargo section of the 65000DWT bulk carrier are shown in Table 2. 
Table 2 Main structure size table

\begin{tabular}{|c|c|c|c|c|c|c|}
\hline Plate & thickness & Plate & thickness & Profile & $\begin{array}{l}\text { Section } \\
\text { modulus }\end{array}$ & type \\
\hline $\begin{array}{l}\text { bottom } \\
\text { plate }\end{array}$ & $15 \mathrm{~mm}$ & $\begin{array}{c}\text { Inner } \\
\text { bottom } \\
\text { board }\end{array}$ & $14 \mathrm{~mm}$ & rib cage & 899.6 & $\mathrm{~T} 500 \times 10+150 \times 12$ \\
\hline $\begin{array}{l}\text { Side outer } \\
\text { panel }\end{array}$ & $15 \mathrm{~mm}$ & $\begin{array}{l}\text { Chinese } \\
\text { coffin }\end{array}$ & $18 \mathrm{~mm}$ & $\begin{array}{l}\text { Strong } \\
\text { beam }\end{array}$ & 376.2 & $280 \times 11 B P$ \\
\hline $\begin{array}{l}\text { Side top } \\
\text { plate }\end{array}$ & $15 \mathrm{~mm}$ & $\begin{array}{l}\text { Side } \\
\text { coffin }\end{array}$ & $15 \mathrm{~mm}$ & $\begin{array}{l}\text { Hatch } \\
\text { longitudinal }\end{array}$ & 327.2 & $280 \times 11 B P$ \\
\hline Side plate & $13 \mathrm{~mm}$ & Solid rib & $15 \mathrm{~mm}$ & $\begin{array}{c}\text { Deck } \\
\text { longitudinal }\end{array}$ & 241.5 & $280 \times 11 B P$ \\
\hline $\begin{array}{c}\text { Deck side } \\
\text { panel }\end{array}$ & $15 \mathrm{~mm}$ & $\begin{array}{c}\text { Watertight } \\
\text { rib }\end{array}$ & $15 \mathrm{~mm}$ & - & - & - \\
\hline $\begin{array}{c}\text { Inner } \\
\text { bottom } \\
\text { plate }\end{array}$ & $14 \mathrm{~mm}$ & $\begin{array}{l}\text { Sloping } \\
\text { plate }\end{array}$ & $13 \mathrm{~mm}$ & - & - & - \\
\hline
\end{tabular}

The determination of each segmental skeleton type is also very important. Through the study of the "hull structure and drawing" course, students have a full understanding of the hull skeleton form, and can basically distinguish the structural characteristics of each typical ship type. Now the 65000DWT bulk carrier The skeleton form of each segment structure is described below.

The bottom structure of the ship adopts a vertical skeleton double-layer bottom structure, and the common solid rib structure is arranged every 3-4 ribs in the lateral direction. The watertight ribs are arranged at the position required for watertightness, and the vertical stiffeners are supported by the solid ribs and the watertight ribs. The bottom longitudinals and the inner soles are made of ordinary flat steel.

The side structure adopts a mixed skeleton single-layer side structure, and the bottom side and top side side structures are longitudinally framed to increase the resistance to total longitudinal bending, while the middle part of the top and bottom tanks is single. The transverse skeletal structure is a strong rib structure.

The deck structure adopts a hybrid skeletal structure, a transverse skeleton structure is adopted between the hatch of the bulk carrier and the hatch, and a longitudinal skeleton structure is adopted for other parts. The hatch end position beam and the hatch longitudinal girders are provided, and the deck strong beam or strong The adjacent spacing of the longitudinal girders is controlled at 3-4 rib positions, and the deck strong beams and the bottom slabs are kept as close as possible to ensure the integrity and continuity of the overall strong members.

Since the cargo tank part of the bulk carrier is selected in this paper, the bulkhead structure adopts the trough-shaped bulkhead and the horizontal concrete structure. The advantage of adopting this structure is that under the condition of ensuring the same strength, the structural weight can be reduced and the material can be saved; Material and bracket structure, which reduces the workload of assembly and welding, is used on bulk carriers, and is also convenient for clearing, thus increasing the loading and unloading efficiency of the cargo. In addition, it is also beneficial to prevent corrosion ${ }^{[4]}$, the determination of the segmented skeleton form as shown in Table 3.

Table 3 segmentation skeleton form

\begin{tabular}{cl}
\hline Segment name & \multicolumn{1}{c}{ Skeleton form and layout requirements } \\
\hline Deck segment & Longitudinal skeleton double bottom structure \\
Side segment & $\begin{array}{l}\text { Horizontal skeleton single-layer side, single skeleton strong } \\
\text { rib structure }\end{array}$ \\
$\begin{array}{c}\text { Bulkhead } \\
\text { segment }\end{array}$ & $\begin{array}{l}\text { Longitudinal structure, horizontal frame structure between } \\
\text { hatchs }\end{array}$ \\
Bottom & Slotted bulkhead structure with horizontal strong skeleton \\
\hline
\end{tabular}


Before the segment structure design, students are required to learn the engineering initialization of the SPD-H hull design system, the basic operations such as plane, curved panel frame and bracket modeling. On this basis, the structural three-dimensional design, each group design model is shown in the figure. 1 is shown.

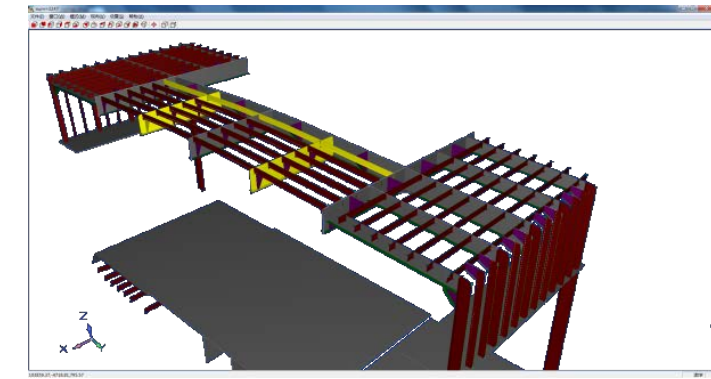

(a) Deck segment

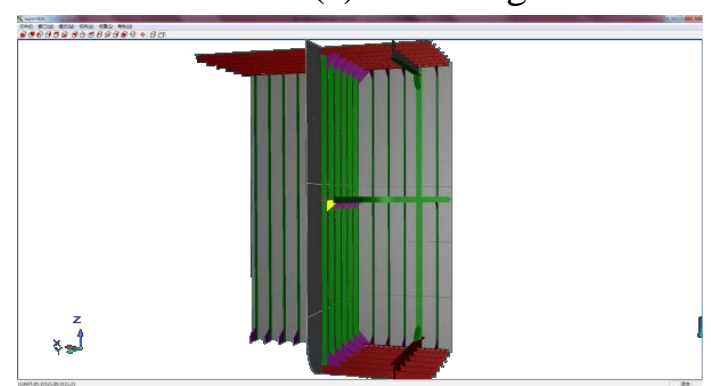

(b) Bulkhead segment

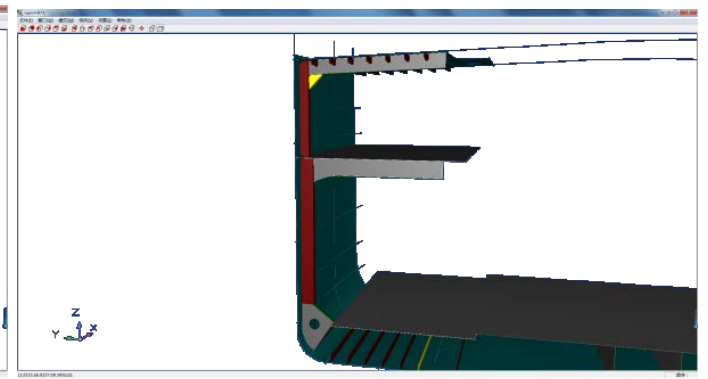

(b) Side segment

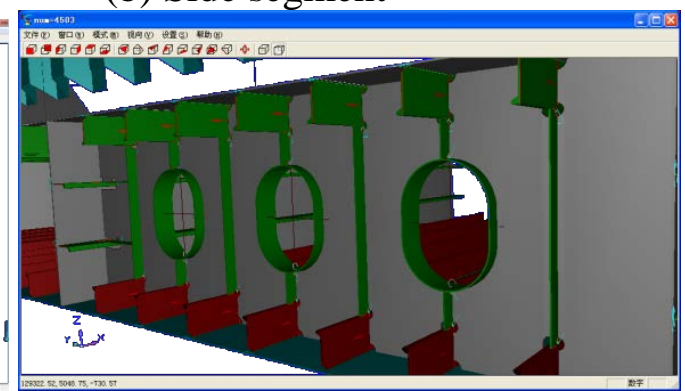

(d) Bottom segment

Figure 1 Three-dimensional structure of the hull section

\section{Summary and Improvement}

By participating in the provincial and national competitions for ship design, it is obvious that the quality of students has improved a lot, and the segmental design and structural analysis can be completed independently. At the same time, the development of teaching materials is the premise and basis of the implementation of the curriculum. At present, there are not many textbooks on the hull structure design on the market, and the teaching materials based on SPD software are rare. Therefore, in the practice of the project-based teaching of the course, compiled supporting materials and teaching videos for project-based teaching.

\section{Conclusion}

(1) Schools and enterprises need to establish deeper cooperation and apply the actual ship type to teaching, so that students can get real exercise in practical projects; as a teacher of the course, they can also lead students to participate in practice based on the platform of engineering and learning. Innovative topics to develop students' professional skills.

(2) Incorporate the certificate into the teaching, and let the enterprise participate in the assessment training through in-depth cooperation with the enterprise. After passing the qualification, the student can obtain the certificate of conformity issued by the school and the enterprise. With this certificate, students can directly enter the company to participate in the actual project.

Of course, teaching reform is a systematic project. It requires long-term continuous efforts and reflections. Through continuous innovation, continuous condensing, and continuous practice, this paper focuses on the teaching design and practice of the practical teaching links of the Course of Ship Structure Design. The curriculum of design and production is also applicable. In the future, the application of the teaching method in other courses and the application of new teaching methods will be continuously tried in the teaching process, so as to improve the teaching quality of the course. 


\section{References}

[1] Yang Baoxiang. Preliminary Study on the Integrated Teaching Mode of "CNC CAD/CAM Application" in Higher Vocational Education [J]. Enterprise Research, 2010.20:140-141.

[2] ZHOU Wei, LU Ping. Research on the Reform of "Ship CAD/CAM" Course in Higher Vocational Colleges [J]. Journal of Nantong Shipping Vocational and Technical College.2011.10 (2):125-128.

[3] China Classification Society. Classification of Steel Seagoing Ships [M]. Beijing: China Communications Press, 2015: 78-105.

[4] Peng Gongwu. Hull structure and drawing [M]. Harbin: Harbin Engineering University Press, 2011: 40-41. 